\title{
Catalytic Biomass to Renewable Biofuels and Biomaterials
}

\author{
Yi-Tong Wang ${ }^{1(D)}$ and Zhen Fang ${ }^{2, *(D)}$ \\ 1 School of Metallurgy and Energy, North China University of Science and Technology, 21 Bohai Avenue, \\ Tangshan 063210, China; wangyt@ncst.edu.cn \\ 2 Biomass Group, College of Engineering, Nanjing Agricultural University, 40 Dianjiangtai Road, \\ Nanjing 210031, China \\ * Correspondence: zhenfang@njau.edu.cn
}

Received: 21 April 2020; Accepted: 26 April 2020; Published: 28 April 2020

check for updates

As the only renewable carbon source, biomass can be converted into biofuels, chemicals, and biomaterials, such as ethanol, butanol, glucose, furfural, biochar, and bio-oils, and is considered as a substitute for fossil oil. The Special Issue "Catalytic Biomass to Renewable Biofuels and Biomaterials" focuses on the introduction of biomass chemical conversion, co-combustion technology, and biological conversion technology to provide guidance for the development and application of biomass energy. This issue includes eleven papers: one review and ten research articles. Glycerol, the main by-product in biodiesel production was acetylated to prepare value-added products from the research results of Bartoli et al. [1]. The conversion of glycerol to acetyl derivatives was facilitated by a heterogeneous catalyst generated from the thermal hydrolysis of biosolids obtained from a municipal wastewater treatment facility. This work can help improve the process economics of renewable diesel production. Based on the most difficult step of the fractionation for lignocellulose-based biorefineries, Hochegger et al. investigated the potential of a base-catalyzed organosoly process as a fractionation technique for European larch sawdust. One particular experimental set (443 K, 30\% v/v MeOH, 30\% w/w NaOH) resulted in the most promising results, with a cellulose recovery of $89 \%$, delignification efficiency of $91 \%$, and pure lignin yield of $82 \%$. The isolated lignin fractions showed promising glass transition temperatures $(\geq 424 \mathrm{~K}$ ) with high thermal stabilities and preferential $\mathrm{O} / \mathrm{C}$ and $\mathrm{H} / \mathrm{C}$ ratios. This, together with high contents of phenolic hydroxyl $(\geq 1.83 \mathrm{mmol} / \mathrm{g})$ and carboxyl groups $(\geq 0.52 \mathrm{mmol} / \mathrm{g})$, indicated a high valorization potential [2]. Sanahuja-Parejo et al. reported the catalytic co-pyrolysis of grape seeds and waste tires for the production of high-quality bio-oils in a pilot-scale auger reactor using different low-cost Ca-based catalysts. The results demonstrated that this upgrading strategy was suitable for the production of better-quality bio-oils with major potential for use as drop-in fuels. In addition, owing to the $\mathrm{CO}_{2}$-capture effect inherent to these catalysts, a more environmentally friendly gas product was produced, comprising $\mathrm{H}_{2}$ and $\mathrm{CH}_{4}$ as the main components [3]. Diesel and jet fuel range cycloalkanes were obtained in $\sim 84.8 \%$ overall carbon yield with cyclopentanone and furfural, which can be produced from hemicellulose. Carbon yield of $86.1 \%$ diesel and jet fuel range cycloalkanes was gained over Pd/H-ZSM-5 catalyst under solvent-free conditions. The cycloalkane mixture obtained with a high density $\left(0.82 \mathrm{~g} \mathrm{~mL}^{-1}\right)$ and a low freezing point $(241.7 \mathrm{~K})$ can be mixed into diesel and jet fuel to increase their volumetric heat values or payloads [4]. Lavarda et al. reported the research for gel-type and macroporous cross-linked copolymers employed in the catalytic hydrolysis of wheat straw pretreated in 1-ethyl-3-methylimidazolium acetate to obtain sugars [5]. Long et al. prepared a highly active, sustainable, and facile catalytic system composed of $\mathrm{K}_{2} \mathrm{CO}_{3}, \mathrm{Ph}_{2} \mathrm{SiH}_{2}$, and bio-based solvent 2-methyltetrahydrofuran to reduce HMF (hydroxymethylfurfural). At a low temperature of $25^{\circ} \mathrm{C}, \mathrm{HMF}$ could be completely converted to 2,5-bis(hydroxymethyl)furan (BHMF) in a good yield of $94 \%$ after $2 \mathrm{~h}$, based on siloxane in situ formed via hydrosilylation [6]. Xu et al. synthesized a 
series of $\mathrm{Ca}(\mathrm{OH})_{2} / \mathrm{Al}_{2} \mathrm{O}_{3}$ catalysts for selectively producing $\mathrm{N}$-containing chemicals from polyethylene terephthalate (PET) via catalytic fast pyrolysis with ammonia process, which can ease environmental problems from PET [7]. The study on the co-combustion of sludge and wheat straw was presented by Xue et al. with results of the blended fuel helping to remedy the defect of each individual component and also to promote the combustion. Addition of sludge could raise the melting point of wheat straw ash and reduce the slagging tendency. Co-combustion restrained the release of $\mathrm{K}$ and transferred it into aluminosilicate and phosphate as well. The release and leaching toxicity of the two heavy metals $(\mathrm{Pb}$ and $\mathrm{Zn}$ ) in the co-combustion were weakened effectively by wheat straw [8]. Benevenuti et al. reported the production of biofuels from fermentation of gases by Clostridium carboxidivorans. In comparison to ATCC®2713 medium, TYA (Tryptone-Yeast extract-Arginine) increased cell growth by $77 \%$, reducing the cost by $47 \%$ and TPYGarg (Tryptone-Peptone-Yeast extract-Glucose-Arginine) increased ethanol production more than four-times, and the cost was reduced by $31 \%$ [9]. The role of humic acid's chemical structure derived from different biomass feedstocks on Fe(III) bioreduction activity was reported by Wei et al. The role that the different compost-derived humic acids played in the dissimilatory Fe(III) bioreduction and chemical structures accelerating Fe reduction was discussed. This study can aid in searching sustainable humic acid-rich composts for wide-ranging applications to catalyzing redox-mediated reactions of pollutants in soils [10]. In a review, Liberato et al. introduced some organisms such as Clostridium carboxidivorans, C. ragsdalei, and C. ljungdahlii used to catalyze the production of biofuels, including ethanol and butanol, and several chemical preparations, such as acetone, 1,3-propanediol, and butyric acid. In this review, literature data showing the technical viability of these processes are presented, evidencing the opportunity to investigate them in a biorefinery context [11].

We are honored to be the Guest Editors of this Special Issue and would like to thank all the authors of this Special Issue, the reviewers for providing us with their valuable comments, the Editor-in-Chief, and all the staff of the Catalysts Editorial Office. We wish to acknowledge the financial support from the Natural Science Foundation of China (No. 21878161) and Nanjing Agricultural University (68Q-0603).

\section{References}

1. Bartoli, M.; Zhu, C.; Chae, M.; Bressler, D. Glycerol Acetylation Mediated by Thermally Hydrolysed Biosolids-Based Material. Catalysts 2020, 10, 5. [CrossRef]

2. Hochegger, M.; Trimmel, G.; Cottyn-Boitte, B.; Cézard, L.; Majira, A.; Schober, S.; Mittelbach, M. Influence of Base-Catalyzed Organosolv Fractionation of Larch Wood Sawdust on Fraction Yields and Lignin Properties. Catalysts 2019, 9, 996. [CrossRef]

3. Sanahuja-Parejo, O.; Veses, A.; López, J.; Murillo, R.; Callén, M.; García, T. Ca-based Catalysts for the Production of High-Quality Bio-Oils from the Catalytic Co-Pyrolysis of Grape Seeds and Waste Tyres. Catalysts 2019, 9, 992. [CrossRef]

4. Wang, W.; Sun, S.; Han, F.; Li, G.; Shao, X.; Li, N. Synthesis of Diesel and Jet Fuel Range Cycloalkanes with Cyclopentanone and Furfural. Catalysts 2019, 9, 886. [CrossRef]

5. Lavarda, G.; Morales-delaRosa, S.; Centomo, P.; Campos-Martin, J.; Zecca, M.; Fierro, J. Gel-Type and Macroporous Cross-Linked Copolymers Functionalized with Acid Groups for the Hydrolysis of Wheat Straw Pretreated with an Ionic Liquid. Catalysts 2019, 9, 675. [CrossRef]

6. Long, J.; Zhao, W.; Xu, Y.; Li, H.; Yang, S. Carbonate-Catalyzed Room-Temperature Selective Reduction of Biomass-Derived 5-Hydroxymethylfurfural into 2,5-Bis(hydroxymethyl)furan. Catalysts 2018, 8, 633. [CrossRef]

7. Xu, L.; Na, X.; Zhang, L.; Dong, Q.; Dong, G.; Wang, Y.; Fang, Z. Selective Production of Terephthalonitrile and Benzonitrile via Pyrolysis of Polyethylene Terephthalate (PET) with Ammonia over $\mathrm{Ca}(\mathrm{OH})_{2} / \mathrm{Al}_{2} \mathrm{O}_{3}$. Catalysts 2019, 9, 436. [CrossRef]

8. Xue, Z.; Zhong, Z.; Zhang, B. Experimental Studies on Co-Combustion of Sludge and Wheat Straw. Catalysts 2019, 9, 182. [CrossRef] 
9. Benevenuti, C.; Botelho, A.; Ribeiro, R.; Branco, M.; Pereira, A.; Vieira, A.; Ferreira, T.; Amaral, P. Experimental Design to Improve Cell Growth and Ethanol Production in Syngas Fermentation by Clostridium carboxidivorans. Catalysts 2020, 10, 59. [CrossRef]

10. Wei, Y.; Wei, Z.; Zhang, F.; Li, X.; Tan, W.; Xi, B. Role of Humic Acid Chemical Structure Derived from Different Biomass Feedstocks on Fe(III) Bioreduction Activity: Implication for Sustainable Use of Bioresources. Catalysts 2019, 9, 450. [CrossRef]

11. Liberato, V.; Benevenuti, C.; Coelho, F.; Botelho, A.; Amaral, P.; Pereira, N.; Ferreira, T. Clostridium sp. as Bio-Catalyst for Fuels and Chemicals Production in a Biorefinery Context. Catalysts 2019, 9, 962. [CrossRef]

(C) 2020 by the authors. Licensee MDPI, Basel, Switzerland. This article is an open access article distributed under the terms and conditions of the Creative Commons Attribution (CC BY) license (http://creativecommons.org/licenses/by/4.0/). 